Article

\title{
Fear, Stress, Resilience and Coping Strategies during COVID-19 in Spanish University Students
}

\author{
Francisco Manuel Morales-Rodríguez
}

check for updates

Citation: Morales-Rodríguez, F.M. Fear, Stress, Resilience and Coping Strategies during COVID-19 in Spanish University Students. Sustainability 2021, 13, 5824. https:// doi.org/10.3390/su13115824

Academic Editor: María del C. Pérez-Fuentes

Received: 23 April 2021

Accepted: 18 May 2021

Published: 21 May 2021

Publisher's Note: MDPI stays neutral with regard to jurisdictional claims in published maps and institutional affiliations.

Copyright: (C) 2021 by the author. Licensee MDPI, Basel, Switzerland. This article is an open access article distributed under the terms and conditions of the Creative Commons Attribution (CC BY) license (https:// creativecommons.org/licenses/by/ $4.0 /)$.
Department of Educational and Developmental Psychology, Faculty of Psychology, University of Granada, Campus Universitario de Cartuja, 18071 Granada, Spain; fmmorales@ugr.es; Tel.: +34-680976924

\begin{abstract}
COVID-19 (2019 coronavirus pandemic) and the resulting confinement has had an impact on mental health and the educational environment, affecting the stress, concerns, fear, and life quality of the university population. This study aimed to examine the correlation between fear of COVID-19, stress with COVID-19, and technological stress in university students, and their resilience, self-esteem, and coping strategies. The final sample comprised 180 Spanish university students, with an average age of 20.76 years $(\mathrm{SD}=4.59$ ). The above-mentioned effects were administered a series of self-report scales. We found statistically significant associations between fear of COVID-19 and stress with COVID-19, technological stress (total score), overload, and complexity (subdimensions of technological stress). Likewise, we found inverse relationships between the students' fear of COVID19 and the use of the coping strategy, cognitive restructuring. Ascertaining the factors that influence the coping strategies of undergraduate university students and their fears, psychological stress, and resilience provides valuable information for the development of educational interventions. This research has relevant implications for the diagnosis, orientation, and design of psycho-educational and clinical interventions that can improve students' well-being and training for effective coping strategies for daily stress and this pandemic situation.
\end{abstract}

Keywords: fear; stress; technological stress; COVID-19; coping strategies; cognitive restructuring

\section{Introduction}

\subsection{Fear and Stress}

Fear is a human emotion with an adaptive function. It helps cope with certain threats; however, it can become maladaptive depending on the situation, intensity, and frequency [1]. When one experiences the fear of the unknown, there is, somehow, a sense that the perceived information is not sufficient for coping with the situation, at any point of processing or level of awareness [1,2]. The 2019 coronavirus pandemic (COVID-19) and the resulting confinement have impacted mental health and the academic environment. Several studies reported that the pandemic has triggered an increase in fears of COVID-19 that contribute to growing levels of stress, anxiety, and depression [1,3-6], and post-traumatic stress [7-9]. In the same vein, other research shows that, specifically, the fear of becoming infected can aggravate anxiety and stress disorders $[9,10]$. Furthermore, in another study, $71.26 \%$ of the participants reported increased levels of stress during the pandemic, and more than half reported that they cannot perceive themselves as capable of coping with pandemic-related stress [6]. The COVID-19 pandemic has been associated with distress, fear of infection, depression, and insomnia both in the general population and among healthcare professionals who may experience increased levels of stress associated with increased suicidal behavior [11].

Other research results revealed that people are afraid of infection, either from the fear of the epidemic itself or of infecting other family members [12]. In addition, it has been found that a longer duration of quarantine may be specifically related to poorer mental health, which contributes to frustration, anxiety, and boredom due to the isolation that 
interferes with daily routine, the provision of inadequate supplies for basic needs, and the insufficient and contradictory information that fails to clarify the steps to follow, the purpose of the quarantine, or the real level of risk, all of which represent stress factors [12]. Similarly, in another study, $53 \%$ of adults in the United States reported being stressed and worried about the coronavirus, as well as sleeping (36\%) or eating problems $(32 \%)$, an increase in alcohol or substance use $(12 \%)$, and worsening of chronic diseases $(12 \%)$ caused precisely by worry and stress about the coronavirus [13]. Negative psychological effects of the COVID-19 pandemic have also been reported for both the general population and healthcare workers who are on the frontlines fighting against the virus [14]. Among the main effects, the authors mention post-traumatic stress symptoms, depression, confusion, and anger. Other stressors include prolonged quarantine, fear of infection, frustration, boredom, inadequate provision of supplies, inadequate information, and financial loss.

In a sample of 304,167 college students, who were administered the Impact of Events Scale 6 (IES-6), 50.9\% reported stress symptoms; $0.5 \%$ reported that they suffer from poor mental health, and 3.2\% reported that they experience poor sleep quality [15]. The students' perceptions of COVID-19 are correlated with psychological stress, self-perceived mental health, and sleep quality, and there are differences in terms of the student demographic characteristics.

Another study revealed several stressors associated with COVID-19 [16]. These include infection-related stressors such as fear when reading or hearing others talking about the severity and contagiousness of COVID-19, the risk of becoming infected or unintentionally infecting others or loved ones, and the degree of self-control of symptoms. Among these symptoms, we can highlight those that are part of a somatic symptom disorder, such as isolation, also leading to other highly stressful factors such as despair, loss of freedom, boredom, insomnia, poor concentration, indecisiveness, irritability, anger, anxiety, anguish, not having physical contact with family and friends, not being able to develop a normal life routine [17], and a higher level of family stress [18].

\subsection{Technological Stress}

A study reported other activity-related stressors associated with COVID-19, such as academic activities that have been affected by changes in daily educational routines such as online tutoring and assessment, non-face-to-face classes, the availability of technological spaces and resources for online teaching, and the large number and possible complexity of assignments requested online, among many others that potentially affect the university student body [16]. This study also revealed other stressors including those related to losses of current job training, education opportunities, or benchmarks (e.g., certification, apprenticeship, internship, and degree completion) and difficulties in obtaining important resources for daily life (e.g., medical care, food, clothing, water, housing, supplies, and prescriptions). Thus, in the university context, it has become necessary to make adjustments to which students must adhere to finish their external practices and their graduation projects; adjustments have also had to be made to other daily routines such as accommodation-related ones, access to university canteens, cheaper sports facilities, and libraries and study rooms. This study also mentions that there may be an increase in the pressure related to the greater or lesser ability to take advantage of social media and to meet the new technological and educational challenges that the current pandemic situation has brought about. Conversely, positive correlations were found between stress levels and Internet use for interpersonal communication and subjective well-being; and the use of the Internet and online tools for leisure have been associated with a higher degree of well-being, although it was precisely for these purposes that the Internet has been used the least by the study sample [19]. Furthermore, university students reported higher levels of stress compared to high school students and the need for the integration of programs to address the students' stress during the distance-learning process has been highlighted [20].

Another recent study [21] highlighted that, given the increased levels of stress during the confinement and the methodological changes, teachers must improve the use of informa- 
tion and communication technologies (ICT) from a neuro-educational approach, focusing on emotional and motivational management, to contribute to a more meaningful learning experience. Some earlier studies had highlighted the positive relationships between workload, techno-stressors, work-family conflict, and behavioral stress [22]. Moreover, the adverse effects of techno-stressors were found to be partly counteracted by strategies that reduce the role played by conflict and overload [23].

From March 11 to 15, 2020, a study conducted in Spain on a sample of 976 individuals reported low levels of stress, anxiety, and depression symptomatology at the beginning of the pandemic [24]. The youngest in the group aged 18-25 years (mostly university students who could be affected by academic and/or technological stress due to online classes, and their need to adapt to new technologies, uncertainty about the evaluation, overload, complexity of online assignments, online assessments, etc.) and people with chronic illnesses showed higher symptomatology. This Basque sample reported higher average levels of stress, anxiety, and depression since March 14, when the population began to feel the effects of the stay-at-home policy. A relevant study indicates that alarming news delivered through ICT can simultaneously affect the emotional dimension in a negative way, causing higher levels of anxiety, stress, frustration, and discomfort due to information overload and the uncertainty raised by the situation [25]. Another recent study conducted on a Spanish population revealed higher levels of confinement stress in women, and especially in people under 25 years of age, demonstrating that those who could combine work or academic activities with on-site work had lower levels of stress compared to those working under other conditions [26].

Research suggests that information technology work such as using video display terminals (VDTs) can have adverse effects, including psychosomatic disorders, mental stress, physical health problems [27,28], job dissatisfaction, and dissatisfaction with life [29]. These problems might be due to multitasking, information, and work overload associated with information and communications technology (ICT) [30]. It was suggested in [31] that the term for the stress people experience from using ICT systems and technologiestechnostress-should be subdivided into stress with negative outcomes (techno-distress) and positive outcomes (techno-eustress). Techno-eustress can improve motivation, satisfaction, and decision making, increasing vitality and joy without generating that stress or imbalances [31].

\subsection{Differences by Gender}

Regarding differences in stress levels and other disorders according to gender, a study on the effects of Covid-19 confinement on mental health and sleeping disorders in an Italian population found that the incidence is higher in women, in people with chronic diseases, and in individuals who spend more time on the Internet and avoid some activities because of peer pressure [32]. In the Australian population, it was also found that women suffered higher levels of stress, depression, and anxiety than men in this pandemic situation [33]. Similarly, a study conducted on a Spanish population revealed that students, women, and people with a lower income and less available space per person in their homes, suffer from a higher psychological impact in terms of emotional distress and deteriorating mental health [34]. Likewise, another study revealed that women, young people, and those who lost their jobs during the health crisis show more negative psychological symptoms such as higher levels of stress [4]. Moreover, the COVID-19 pandemic and the resulting confinement have been especially stressful for women, younger adults under 35 years of age, and people who are unemployed and have lower incomes [3]. Using Cohen et al.'s scale, another study reported higher levels of perceived stress in women compared to men [35]. Another recent study [36] found that university students frequently experience academic stress and have poor coping skills overall. They found that the male students had significantly better passive problem- and emotional-coping behaviors than the female students, and the female students had significantly better active problem-coping behaviors. 


\subsection{Coping Strategies, Self-Esteem, and Resilience}

Coping has been considered a complex multidimensional process [37]. One of the pioneering definitions of coping described it as a process that is activated by the perception of a threat, to regulate the resulting emotional conflict and eliminate the threat [38]. Subsequently, a correlation was drawn between stress and coping; the latter is defined as "cognitive and behavioral efforts, constantly changing, to manage specific external or internal demands perceived as surplus or exceeding the individual's resources" [39] (p. 164).

Coping strategies are conscious and voluntary efforts to moderate emotions, behaviors, cognitions, psychophysiology, and environmental variables in response to the stress caused by daily events or circumstances [40-42]. These resources involve two personal dimensions: the internal dimension that is linked to dispositional variables, heredity, age, and gender, and the external dimension that is associated with actions in response to the demands of a specific situation or sociocultural environment. Both dimensions interact by predisposing the subjects to specific and characteristic behaviors [43].

In terms of typologies of strategies, Lazarus and Folkman pioneered a distinction between problem-focused coping strategies (modifying or managing the source of the problem by actively seeking a solution), and coping strategies focused on reducing the relevant emotions [39]. This research adopted a typology of three basic styles distinguished by Frydenberg and Lewis: (1) problem-focused style that involves concentrating on solving the problem, striving and succeeding, focusing on the positive, relaxing diversions, and physical distraction; (2) in relation to others, including social support, making close friends, seeking to belong, social action, seeking spiritual and professional support; and (3) unproductive, encompassing worrying, wishful thinking, avoiding or ignoring the problem, stress reduction, self-blame, and keeping it to oneself $[44,45]$ and it was found that individuals with "external" and "developer" styles reported higher stress levels during problem-solving. Furthermore, those with an "external" style or a "task-oriented problemsolving style" were more likely to use restraint as a coping strategy. It was surmised that individuals' styles influence their problem-solving strategies, such as asking for help ("external style"), new thinking ("explorer style"), or making "hard" choices ("task-oriented decision-making style").

It is important to assess the coping strategies used, as they relate to the adjustment and mental health of children, youth, and adolescents. There have been more studies evaluating coping strategies among children and adolescents than university students. Although university students could be considered to be in "late adolescence," the studies of children and adolescents' coping strategies can best be applied to university students by examining how coping strategies evolve in different developmental stages. Different strategies yield different adaptation and mental health results. Thus, many authors have found a relationship between the strategies used, stressful situations, and a prognosis of psychopathology and maladjustment or, conversely, mental health in children [46-49]. In fact, some of these studies found that the use of productive coping strategies when facing problems, such as those concerning school coexistence and deteriorating interpersonal relationships, currently frequent in schools, is associated with more favorable results of socio-emotional adaptation and a higher degree of adaptation and psychological well-being [50,51], as well as being able to reduce potential illnesses and increases in the likelihood of achieving and maintaining better levels of health and life quality [37,52]. In contrast, unproductive strategies are associated with emotional maladjustment $[48,49,53,54]$, as well as socioemotional and school misfit [49,55]. Finally, avoidance-type strategies are associated with depressive symptoms, higher levels of aggressive behavior, and self-reported anxiety [56].

Various studies specifically evaluated the coping strategies employed during the pandemic. For example, a recent study was conducted on the use of both emotion-based and problem-focused coping strategies (seeking social support, compassion, acceptance, and mental disengagement) on a sample of Pakistani university students aged 19-25 years; the results revealed that women and those with higher levels of anxiety are more likely to use social support and compassion-seeking strategies [57]. Another study conducted 
with a sample of Chinese international students revealed that the students experience more than a moderate level of direct and indirect pandemic-related stress and that identification with Chinese cultural beliefs may help regulate negative emotions and the use of positive and active coping strategies for the pandemic. Furthermore, the increased level of psychological distress was higher in a sample Chinese population for people who use a passive coping style and perceive less social support [58]. In a sample Australian population, the coping strategies associated with better mental health were reported as positive reframing (strategies focused on positive emotions) and acceptance and humor; whereas the coping strategies of self-blaming, venting, behavioral disengagement, and self-distraction are associated with poor mental health [33].

Another study revealed that, in a sample of university students, the levels of academic stress were the same before and after the COVID-19 outbreak. Likewise, the coping strategy of high levels of information seeking has been associated with adequate risk perception and higher levels of well-being in students [59].

Consistent with this result, earlier research highlights the relationships between strategies of coping with stress and emotional disorders such as anxiety [60] and depression [61]. Other recent studies that review several papers from indexed journals also suggested that problem-approaching and positive-focused coping strategies tend to be associated with a higher state of well-being $[62,63]$.

Researchers have considered effective emotional regulation as an appropriate model, specifically when examining the role of pro-social behavior as a coping mechanism [64]. Emotional regulation could be considered as an affective, cognitive, and behavioral process through which an individual influences both their emotional experience and expression [65]. There is still no consensus on the definition of the construct of emotional regulation. Thompson [66] (1991, p. 269) wrote that "Emotional regulation refers to the extrinsic and intrinsic processes responsible for monitoring, evaluating, and modifying emotional reactions." However, this paper is framed within the multidimensional model proposed by Gratz and Roemer (2004) [67]: "emotion regulation encompasses the: (a) awareness and understanding of emotions; (b) acceptance of emotions; (c) ability to control impulsive behaviors and behave in accordance with desired goals when experiencing negative emotions; and (d) ability to use situationally appropriate emotion regulation strategies flexibly to modulate emotional responses as desired in order to meet individual goals and situational demands" (pp. 42-43). Recent studies have examined this approach or perspective [68].

It is necessary to examine the role of emotions in the management of victimization [69]. Current research on victimization may benefit from examining emotional regulation, because variations in emotional regulation and responsiveness may, in part, explain the differences in children's adjustment to peer victimization.

Negative emotional responses could lead to ineffective coping [70]. Less emotional regulation can be associated with more negative social behaviors towards peers [71]. The significantly fewer studies examining positive emotional responses and coping in stressful situations reveal low levels of internalization of problems [72]. The ability to self-regulate decreases the effects of stress on children's adjustment [73]. Furthermore, the ability to control negative emotions can be integral to the development of pro-social behaviors [74].

A series of experiments during the pandemic situation revealed that the general belief in a just world is an emotional factor in pandemic and non-pandemic situations, since it enhances positive emotions and reduces negative emotions [75].

Furthermore, self-regulation is also predictive of active responding (approach). In addition, previous findings indicate that a positive appraisal of a stressful situation (the belief that one can cope with the situation) is often predictive of active coping [72].

\section{Self-Esteem and Resilience}

Problem-focused coping strategies such as active solution, positive attitude, and seeking information and guidance are mostly employed by those who identify themselves as having better academic self-concept, social skills, and emotional intelligence [76]. Further- 
more, self-concept and resilience predict a positive adjustment or adaptation of college students [77], and reduced levels of self-concept and resilience are associated with higher ruminating scores [78]. While it is evident that coping with daily stressful situations should be considered as a variable in the design of future training programs, more studies are required to further investigate both the operational definitions of these constructs and the relationship that self-esteem may have with other psychoeducational variables [79].

Self-esteem "refers more to the affective response one gives to how one sees oneself, that is, one's evaluation or assessment of oneself" [80] (p. 14). Defining self-concept implies answering the question "Who am I?" by identifying psychological, social, and physical characteristics of an individual [81] (p. 97). From a more theoretical point of view, selfesteem can be considered one of the components of self-concept, namely, the affective and evaluative components [82]. According to Rosenberg's scale that has been applied as an instrument to evaluate this variable in the present research, it can be defined as the valuative dimension of self-concept, i.e., the set of feelings and thoughts of personal worth and self-respect [83]. This scale allows us to obtain an overall unidimensional total score of the variable self-esteem.

With respect to the specific pandemic situation, a former study conducted on a group of students revealed that collective self-esteem diminishes perceived stress because social support increases and anxiety levels decrease [84]. Furthermore, the fear of COVID-19 has a negative effect on psychological adjustment in individuals, and especially in healthcare professionals, whereas psychological resilience has a protective function that limits the effect [85]. Another recent study developed during the pandemic reported that age and educational level are positively correlated with resilience, while perceived stress level is negatively correlated with that variable [86].

There are studies that emphasize the importance of resilience to improve personal development, quality of life [87], and orientation of university students [88]. Few studies have focused on these constructs within the university environment. A factor or characteristic that can be recognized in resilient students is self-esteem [87,89-91]. The difficulties that can produce resilience in university students include the stress generated by the number of classes, internship schedules, and not having a scholarship [92]. In [36] it was found that worries about the future and low self-esteem were associated with academic stress.

The United Nations Educational, Scientific, and Cultural Organization (UNESCO) [93], the Organization for Economic Cooperation and Development (OECD) [94], and models such as EuroPsy [95] consider the importance of developing the inner and interpersonal skills related to the capacity for resilience, training in coping strategies for daily stress, and improving other socioemotional skills related to enhancing esteem and emotional management. It has been found that age and level of education are positively associated with resilience, while the highest level of perceived stress, reporting the need for help from relatives and neighbors, and the total number of days locked up are negatively correlated with resilience [86]. Furthermore, resilience and coping strategies have mediating effects on stopping unpleasant emotions, thoughts, and problem-focused strategies to reduce the effect of stress [96]. A strategy comprising a higher degree of concern about COVID19 , the number of hours spent on acquiring information about COVID-19, or the need for psychological support are predictors of greater psychological distress [97]. Similarly, resilience is negatively correlated with the presence of symptoms of depression, anxiety, and somatization [98].

\subsection{Hypothesis and Aims}

The hypothesis was as follows: High levels of fear of COVID-19, stress with COVID-19, and technological stress are expected to be found in undergraduate university students; statistically significant correlations are expected between fear of COVID-19, stress with COVID-19, technological stress, and resilience, self-esteem, and coping strategies. The current study investigated the associations between the variables that were selected for the research. 


\section{Materials and Methods}

\subsection{Design}

This was an ex post facto and transversal study and employed a convenience sample of participating students. Participants were asked to complete a series of self-report scales. The data were analyzed using correlation and multiple regression statistics. The study was conducted between April and May 2020.

\subsection{Participants}

The initial sample group comprised 202 students. The final sample comprised 180 teenagers who provided, in writing in the corresponding box, their consent to participate in the study. The data were excluded for those who had not completed each questionnaire and those who were part-time students and had special educational needs (SEN). We worked with an incidental balanced sample by gender. It was carried out using G*power 3.1 software (version 3.1, Institut für Experimentelle Psychologie, Düsseldorf, Germany). This proved that a sample size of 151 students was needed to provide a confidence interval of $95 \%$, with a power of $95 \%$, assuming a bilateral significance level $(\alpha)$ of 0.05. This study protocol was approved by the Ethics Committee.

\subsection{Instruments}

Fears of COVID-19. The FCV-19S is a seven-item unidimensional scale with a fivepoint scale response format of 1 (strongly disagree) to 5 (strongly agree) that assesses fears of COVID-19 among the general population [99]. It has adequate psychometric properties. This measure showed a suitable internal validity (Cronbach's alpha of 0.85 ) for our sample. An example of an item of the scale is "I am very afraid of the coronavirus (COVID-19)." The scale has been internationally confirmed [5].

To assess stress with COVID-19, we employed a modified version of Cohen et al.'s Perceived Stress Scale related to COVID-19 (EPP-10-C) [100] that comprises 10 items assessed on a five-point Likert scale: never, almost never, occasionally, almost always, and always. Its cutoff point, $\geq 25$, shows high perceived stress related to COVID-19 during the past seven days. A Cronbach's $\alpha$ of 0.83 was found in this study. An example of an item from this scale is "I have felt nervous or stressed about the epidemic."

To measure technological stress (technostress) [101], this study used an abbreviated scale consisting of 11 items assessed on a five-point Likert-scale where $1=$ Strongly Disagree, 2 = Disagree, 3 = Neither Disagree nor Agree, $4=$ Agree, $5=$ Strongly Agree. It consists of three dimensions: technological overload (four items), techno-invasion (three items), and techno-complexity (four items). In the present sample, Cronbach's alpha was 0.91 for the techno-overload dimension (e.g., "I am forced by technology to work much faster"); 0.87 for techno-invasion (e.g., "I spend less time with my family due to technology"), and 0.93 for techno-complexity (e.g., "I need a long time to understand and use new technologies"). Cronbach's alpha for the instrument was 0.88 .

Resilience Scale. The scale provided by [102,103] has been used in this study. This scale has 14 items based on the Likert scale ranging from 1 (strongly disagree) to 7 (strongly agree). The instrument has two factors. The first factor, personal competence, consists of one item; and the second factor, acceptance of oneself and life, consists of three items. For the current sample, Cronbach's alpha was measured as 0.81. An example of an item for the personal competence factor in this instrument is "I feel proud of the things I have achieved" and an example for acceptance of oneself and life is, "In general, I take things calmly."

The Rosenberg Self-Esteem Scale (RSES) [104] measures global self-esteem. This instrument includes items whose answers are rated on a Likert scale that ranges from 1 to 4 where $1=$ Strongly disagree and $4=$ Strongly agree. This scale has been widely administered (e.g., [105]). Cronbach's alpha for internal consistency or reliability in this study was 0.86 . An example of an item for this instrument is, "I'm convinced that I have good qualities."

The Inventory of Coping Strategies adapted by Cano [106] has been a practical model in understanding how people handle the stressors in their lives. With a focus on coping 
strategies, two complementary (not opposing) concepts were developed on how individuals manage stressors: one related to coping styles and the other to coping strategies themselves. This method was developed from the Coping Modes Scale, and we made an improvement to this scale.

The adaptation is due to the limitations of instruments available in Spanish; the original inventory comprising 72 items was modified into 40 items. Through this method, two types of information were collected: qualitative, in which the individual talks about the stressful situation; and quantitative, which is a measure of the frequency of the use of certain coping strategies and the level of perceived effectiveness in coping, according to a Likert scale. Consequently, both narratives and scores were obtained.

The items that constituted the scale include "I blamed myself" and "I spent some time alone." The items were scored on a scale from 0 to 4 , where 0 is "Not at all" and 4 is "Totally." This instrument demonstrated adequate psychometric properties of reliability and validity. The scale demonstrated an internal consistency of 0.67 for the cognitive approach coping strategy, 0.66 for the behavioral approach coping strategy, 0.58 for the cognitive avoidance coping strategy, and 0.57 for the behavioral avoidance coping strategy.

\subsection{Procedure}

While applying the questionnaires, we ensured the anonymity and confidentiality of participants. They were informed that they could leave the study at any time without any explanation. We obtained the informed consent of the participants. The average time to complete the questionnaires was about $19 \mathrm{~min}$.

After obtaining the data, we performed a statistical analysis, using an ex post facto design. The analysis was carried out with the computerized statistical package SPSS 22.0. An exploration (descriptive statistics and Kolmogorov-Smirnov normality tests) of the study variables and the fulfillment of the assumptions of normality and non-collinearity for Pearson's correlation were performed.

The analyses of the relationships between the quantitative variables were carried out using Pearson's correlation analysis and linear regression to itself as descriptive analysis, as well as Pearson's correlation between the variables. Finally, the Student $t$-test was applied to independent samples to analyze statistically significant differences between students according to gender.

\subsection{Data Analysis}

The SPSS version 22 software package (IBM Corp., Armonk, NY, USA) was employed for data analyses. The descriptive analysis was estimated, and the normal distribution of variables was examined using the Kolmogorov-Smirnov test. A scatter diagram was used to examine compliance with the assumptions of linearity and homoscedasticity. Pearson's correlation examined the association between fear of COVID-19, stress with COVID-19, technological stress related to COVID-19, and resilience, self-esteem, and coping strategies.

Normality of residuals, homogeneity of variance for residuals, and linearity of data were analyzed to complete the multiple linear regression analyses. A $p<0.05$ was used as the significance level. Multiple linear regression analyses were conducted to define the relationships between fear of COVID-19, stress with COVID-19, technological stress associated with COVID-19, resilience, self-esteem, and coping strategies.

\section{Results}

\section{Descriptive Statistics of the Study Variables}

The final sample comprised 180 individuals who had completed all the questionnaires. Of the 180 students, $61.00 \%$ were women, and $39.00 \%$ were men, most of whom were single and aged 18-24 years, with an average age of 20.76. In terms of marital status, $59.2 \%$ were single, and $36 \%$ had a partner. Regarding the number of people living in the family home, $43.2 \%$ of the cases had four people living in the family house; $15.2 \%$ had two, $15.2 \%$ had three. The majority had a medium socioeconomic status. 
Table 1 shows the results of all the tests applied: the maximum and minimum scores of each test and the average of the values obtained from the answers of the participants, with their corresponding standard deviation (descriptive statistics).

Table 1. Descriptive statistics of fear of COVID-19, resilience, stress with COVID-19, technological stress, self-esteem, and coping strategies.

\begin{tabular}{cccccc}
\hline Variables & Min & Max & Mea & Median & SD \\
\hline Fear of COVID-19 & 7.00 & 30.00 & 14.90 & 14.00 & 5.77 \\
\hline Resilience & & & & & \\
Personal competence & 22.00 & 77.00 & 61.61 & 63.00 & 9.12 \\
Acceptance of oneself and life & 7.00 & 21.00 & 14.75 & 15.00 & 3.08 \\
\hline Stress with COVID-19 & 11.00 & 47.00 & 30.96 & 32.00 & 8.70 \\
\hline Technological stress (total) & 10.00 & 49.00 & 29.55 & 30.50 & 8.17 \\
Technological overload & 4.00 & 20.00 & 12.55 & 13.00 & 3.77 \\
Techno-invasion & 3.00 & 15.00 & 10.11 & 11.00 & 3.27 \\
Techno complexity & 4.00 & 20.00 & 9.01 & 8.00 & 4.51 \\
\hline Self-esteem & 11.00 & 40.00 & 23.00 & 20.00 & 10.01 \\
\hline Coping strategies & & & & & \\
Problem solving & 11.00 & 25.00 & 19.84 & 20.00 & 3.42 \\
Self-criticism & 5.00 & 25.00 & 15.52 & 16.00 & 5.45 \\
Emotional expression & 6.00 & 30.00 & 21.36 & 22.00 & 4.90 \\
Desiderative thinking & 5.00 & 20.00 & 16.46 & 18.00 & 3.59 \\
Cognitive restructuring & 6.00 & 25.00 & 17.03 & 17.00 & 4.22 \\
Avoidance of problems & 4.00 & 20.00 & 10.50 & 10.50 & 3.74 \\
Social withdrawal & 8.00 & 23.00 & 16.09 & 16.00 & 2.79 \\
\hline
\end{tabular}

The mean score obtained for the fear of COVID-19 variable was 14.90. The scores on this scale can vary from 7 to 35 points; the higher the score, the greater the students' fear of COVID-19.

The scores for the variable resilience regarding the pandemic situation were low in this group of university students, considering that the maximum range of the score is 98 points. The mean scores for the personal competence and acceptance of oneself and life factors were 61.61 and 14.75 , respectively.

The mean score for the stress with COVID-19 variable for this group of students was 30.96. Considering that the cut-off point, $\geq 25$, shows high perceived stress related to COVID-19, this sample demonstrated high perceived stress levels.

The existence of technological stress was also present, especially in the dimensions of technological overload and techno-invasion where averages of 12.55 and 10.11 were observed, respectively.

The coping strategies most frequently used by the students to deal with the pandemicrelated stress were emotional expression with an average score of 21.36, problem solving with an average of 19.84, and cognitive restructuring with an average of 17.03.

Table 2 displays the analysis of the differences among the fear of COVID-19, resilience, stress with COVID-19, technological stress, self-esteem, and coping strategies according to gender.

The variable with the greatest difference between genders was the fear of Covid-19 and stress with COVID-19, with a higher score in both variables in the case of women (Table 2). Regarding coping strategies, we also found statistically significant differences according to gender. Specifically, the emotional expression strategy was used, on average, more by women than by men during the Covid-19 pandemic.

Table 3 shows the correlations among the variables: fear of COVID-19, resilience, stress with COVID-19, technological stress, self-esteem, and Coping strategies. 
Table 2. Means (Student $t$-tests) for gender.

\begin{tabular}{ccccccccc}
\hline \multirow{2}{*}{ Variables } & \multicolumn{3}{c}{ Men } & \multicolumn{3}{c}{ Women } & \multicolumn{4}{c}{ Student $\boldsymbol{t}$-Test } \\
\cline { 2 - 9 } & $\boldsymbol{M}$ & $\boldsymbol{S D}$ & $\boldsymbol{M}$ & $\boldsymbol{S D}$ & $\boldsymbol{t}$ & $\boldsymbol{d f}$ & $\boldsymbol{p}$ & $\boldsymbol{d}$ \\
\hline Fear of COVID-19 & 13.23 & 4.87 & 15.67 & 6.01 & -4.64 & 178 & 0.03 & -2.43 \\
Personal competence & 63.54 & 7.24 & 60.71 & 9.82 & -1.64 & 178 & 0.21 & 2.83 \\
Acceptance of oneself and life & 2.86 & 1.81 & 4.34 & 2.46 & -1.09 & 178 & 0.57 & 0.44 \\
Stress with COVID-19 & 28.31 & 8.50 & 32.18 & 8.57 & -7.19 & & 0.02 & -3.87 \\
Technological stress (total) & 28.65 & 7.89 & 29.96 & 8.30 & -4.46 & & 0.41 & -1.30 \\
Technological overload & 12.57 & 3.65 & 12.53 & 3.85 & -1.43 & & 0.95 & 0.04 \\
Techno-invasion & 9.81 & 3.65 & 10.24 & 3.08 & -1.70 & 0.50 & -0.43 \\
Techno-complexity & 8.16 & 4.21 & 9.40 & 4.62 & -2.99 & & 0.16 & -1.24 \\
Self-esteem & 22.75 & 9.56 & 23.29 & 10.31 & -5.51 & & 0.82 & -0.54 \\
Problem solving & 19.44 & 3.40 & 20.02 & 3.44 & -1.95 & & 0.40 & -0.58 \\
Self-criticism & 15.27 & 4.79 & 15.63 & 5.76 & -2.54 & 0.75 & -0.35 \\
Emotional expression & 20.05 & 5.14 & 21.97 & 4.69 & -3.85 & & 0.05 & -1.91 \\
Desiderative thinking & 15.55 & 3.71 & 16.89 & 3.47 & -2.76 & & 0.06 & -1.34 \\
Cognitive restructuring & 17.19 & 3.63 & 16.96 & 4.50 & -1.46 & & 0.78 & 0.23 \\
Avoidance of problems & 10.94 & 2.88 & 10.28 & 4.07 & -0.84 & & 0.38 & 0.65 \\
Social withdrawal & 15.69 & 2.95 & 16.28 & 2.71 & -1.71 & & 0.29 & -0.59
\end{tabular}

$\overline{d f}$ : degrees of freedom; $p$ : significance; $t$ : $t$ de student; $d$ : difference in averages; $M$ : mean; SD: standard deviation.

Table 3. Correlations between fear of COVID-19, resilience, stress with COVID-19, technological stress, self-esteem, and coping strategies.

\begin{tabular}{|c|c|c|c|c|c|c|c|c|c|c|c|c|c|c|c|c|}
\hline & 1 & 2 & 3 & 4 & 5 & 6 & 7 & 8 & 9 & 10 & 11 & 12 & 13 & 14 & 15 & 16 \\
\hline 1 & 1 & -0.10 & 0.01 & $\underset{* *}{0.42}$ & $\underset{* *}{0.24}$ & $0.21 *$ & 0.14 & $0.20 *$ & 0.01 & -0.17 & -0.03 & -0.13 & -0.05 & -0.20 & -0.11 & -0.07 \\
\hline 2 & -0.10 & 1 & $\underset{* *}{0.63}$ & -0.12 & 0.14 & 0.14 & 0.13 & 0.07 & -0.07 & $\underset{* *}{0.38}$ & -0.09 & -0.02 & -0.02 & -0.04 & 0.09 & -0.03 \\
\hline 3 & 0.01 & $\underset{* *}{0.63}$ & 1 & -0.03 & 0.15 & 0.15 & 0.04 & 0.12 & -0.12 & $\underset{* *}{0.42}$ & -0.16 & 0.18 & -0.09 & 0.06 & 0.11 & -0.16 \\
\hline 4 & $\underset{* *}{0.42}$ & -0.12 & -0.03 & 1 & $\underset{* *}{0.42}$ & $\underset{* *}{0.38}$ & $\begin{array}{c}0.33 \\
* *\end{array}$ & $\underset{* *}{0.25}$ & 0.02 & -0.02 & -0.05 & -0.15 & -0.07 & -0.09 & -0.06 & -0.12 \\
\hline 5 & $\begin{array}{c}0.24 \\
* *\end{array}$ & 0.14 & 0.15 & $\begin{array}{c}0.42 \\
* *\end{array}$ & 1 & $\begin{array}{c}0.82 \\
* *\end{array}$ & $\underset{* *}{0.74}$ & $\underset{* *}{0.70}$ & 0.12 & $\underset{*}{-0.24}$ & 0.15 & -0.17 & 0.03 & -0.13 & -0.05 & -0.08 \\
\hline 6 & $0.21 *$ & 0.14 & 0.15 & $\underset{* *}{0.38}$ & $\underset{* *}{0.82}$ & 1 & $\underset{* *}{0.53}$ & $\underset{* *}{0.33}$ & 0.08 & $-\underset{* *}{-0.23}$ & 0.16 & $\underset{*}{-0.21}$ & -0.01 & -0.12 & -0.14 & -0.07 \\
\hline 7 & 0.14 & 0.13 & 0.04 & $\underset{* *}{0.33}$ & $\underset{* *}{0.74}$ & $\begin{array}{c}0.53 \\
* *\end{array}$ & 1 & $\underset{* *}{0.33}$ & 0.11 & $\underset{*}{-0.19}$ & 0.18 & 0.04 & 0.04 & 0.04 & 0.03 & -0.14 \\
\hline 8 & 0.20 * & 0.07 & 0.12 & $\begin{array}{c}0.25 \\
* *\end{array}$ & $\underset{* *}{0.70}$ & $\underset{* *}{0.33}$ & $\underset{* *}{0.33}$ & 1 & 0.10 & -0.12 & -0.00 & -0.08 & -0.07 & $\begin{array}{c}-0.22 \\
*\end{array}$ & 0.01 & 0.02 \\
\hline 9 & 0.01 & -0.07 & -0.12 & 0.02 & 0.12 & 0.08 & 0.11 & 0.10 & 1 & -0.02 & -0.02 & 0.07 & -0.02 & 0.11 & 0.00 & 0.08 \\
\hline 10 & 0.17 & $\begin{array}{c}0.38 \\
* *\end{array}$ & $\underset{* *}{0.42}$ & -0.02 & $\begin{array}{c}-0.24 \\
*\end{array}$ & $\underset{* *}{-0.23}$ & $\underset{*}{-0.19}$ & -0.12 & 0.02 & 1 & -0.10 & $\begin{array}{c}0.37 \\
* *\end{array}$ & -0.06 & $\underset{* *}{0.39}$ & 0.00 & -0.01 \\
\hline 11 & -0.03 & -0.09 & -0.16 & -0.05 & 0.15 & 0.16 & 0.18 & -0.00 & -0.02 & -0.10 & 1 & -0.01 & $\underset{* *}{0.34}$ & 0.13 & 0.03 & $\underset{* *}{0.28}$ \\
\hline 12 & -0.13 & -0.02 & 0.18 & -0.15 & -0.17 & $0.21 *$ & 0.04 & -0.08 & 0.07 & $\underset{* *}{0.37}$ & -0.01 & 1 & 0.13 & $0.22 *$ & 0.03 & 0.13 \\
\hline 13 & -0.05 & -0.02 & -0.09 & -0.07 & 0.03 & -0.01 & 0.04 & 0.07 & -0.02 & -0.06 & $\underset{* *}{0.34}$ & 0.13 & 1 & 0.01 & -0.01 & $\underset{* *}{0.35}$ \\
\hline 14 & $\underset{*}{-0.20}$ & -0.04 & 0.06 & -0.09 & -0.13 & -0.12 & 0.04 & $-0.22^{*}$ & 0.11 & $\underset{* *}{0.39}$ & 0.13 & $0.22 *$ & 0.01 & 1 & $\underset{* *}{0.30}$ & 0.03 \\
\hline 15 & -0.11 & 0.09 & 0.11 & -0.006 & -0.05 & -0.14 & 0.03 & 0.01 & 0.00 & 0.00 & 0.03 & 0.03 & -0.01 & $\underset{* *}{0.30}$ & 1 & 0.01 \\
\hline 16 & -0.07 & -0.03 & -0.16 & -0.12 & -0.08 & -0.07 & -0.14 & 0.02 & 0.08 & -0.01 & $\underset{* *}{0.28}$ & 0.13 & $\underset{* *}{0.35}$ & 0.03 & 0.01 & 1 \\
\hline
\end{tabular}

${ }^{*} p<0.05 ;{ }^{* *} p<0.01 ; 1$ Fear of COVID-19; 2 . Personal competence; 3 . Acceptance of oneself and of life; 4. Stress with COVID-19; 5. Technological stress (total); 6. Technological overload (technological stress); 7. Techno-invasion (technological stress); 8. Technocomplexity (technological stress); 9. Self-esteem; 10. Problem solving; 11. Self-criticism; 12. Emotional expression; 13. Desiderative thinking; 14. Cognitive restructuring; 15. Avoidance of problems; 16. Social withdrawal.

We found statistically significant associations between the variables of fear of COVID-19, stress with COVID-19, technological stress (total), technological overload (technological stress), and techno-complexity (technological stress). We also found inverse relationships between the fear of COVID-19 in students and the use of the coping strategy cognitive restructuring.

The variable resilience, comprising personal competence and acceptance of oneself and life, was found to be positively correlated with the coping strategy problem solving. 
We found statistically significant associations between stress with COVID-19 and technological stress (both in its total score and in its three dimensions, namely, technological overload, techno-invasion, and techno-complexity.)

Technological stress (Technological overload and techno-invasion) was found to be negatively correlated with a greater use of the coping strategy problem solving. Likewise, the technological overload dimension was also found to be negatively correlated with the coping strategy emotional expression, and the techno-complexity dimension was found to be negatively correlated with cognitive restructuring.

The personal competence (Resilience) and acceptance of oneself and life (Resilience) were significantly related to the dependent variable, predicting $24.0 \%$ of the total variance $\left(\mathrm{R}^{2}=0.240, \mathrm{~F}(2267)=2.267, p<0.001\right)$ of the problem-solving strategy (Table 4$)$.

Table 4. Regression of problem solving from the variables fear of COVID-19, resilience, stress with COVID-19, technological stress, and self-esteem.

\begin{tabular}{ccccccc}
\hline \multicolumn{7}{c}{ Problem Solving $\left(\mathbf{R}^{2}=\mathbf{0 . 2 4 0}\right)$} \\
\hline Independent Variables & B & \multicolumn{9}{c}{$\mathbf{9 5 \%}$ CI } & $\beta$ & $S E$ & $p$-Value \\
\hline \multicolumn{7}{c}{$\begin{array}{l}\text { Lower Upper } \\
\text { Limit Limit }\end{array}$} \\
\hline $\begin{array}{c}\text { Personal competence } \\
\text { (Resilience) }\end{array}$ & 0.13 & -0.23 & 0.02 & 0.33 & 0.05 & 0.02 \\
$\begin{array}{c}\text { Acceptance of oneself and life } \\
\text { (Resilience) }\end{array}$ & 0.47 & 0.15 & 0.79 & 0.42 & 0.16 & 0.00 \\
\hline
\end{tabular}

$\mathrm{R}^{2}$ : determination regression coefficient; B: estimators of regression coefficients; $\beta$ : estimators of standardized regression coefficients; $95 \% \mathrm{CI}$ : $95 \%$ confidence interval for $\mathrm{B} ; \beta$ : adjusted coefficient of multiple linear regression analysis; SE coefficient standard error; $p$ : level of critical significance.

\section{Discussion}

This study investigated the correlations between fear of COVID-19, stress with COVID19, technological stress associated with COVID-19, resilience, self-esteem, and coping strategies among undergraduate university students. Indeed, students and women have suffered the most psychological impact due to the confinement generated by the pandemic [4,32-34].

The results in the present sample showed high levels of daily stress, technological stress with different dimensions, and fear of COVID-19 in this pandemic situation. These data are consistent with those obtained in previous studies that assess how pandemics, such as COVID-19, heighten levels of stress, fear, and strong emotions that exceed normal levels of intensity and frequency [1,107-109] in people who sometimes do not perceive themselves as capable of sufficient resilience to cope with those feelings [6]. In fact, the scores obtained in the self-perceived resilience variable in the present sample can be considered rather low when coping with the situations generated by the pandemic. Moreover, the study sample comprised young university students who are in an age group adapting to the university environment, who, like other cultures facing this pandemic situation, may experience more fear [110], and become more vulnerable to information overload and unreliable opinions on social media [6].

Likewise, we found inverse relationships between the students' fear of COVID-19 and the use of the coping strategy, cognitive restructuring. The importance of training for coping strategies to deal with fear and stress, such as the cognitive restructuring strategy, has been pointed out by professional schools of psychology and in different research studies, especially in primary and secondary education [1]. Although studies on this subject are still scarce in our context, in research conducted with Chinese citizens aged 18 and older, fewer mental health problems were reported by those who were less exposed to the media and who more frequently use cognitive re-evaluation and pro-social cognitive coping strategies [111]. 
Indeed, cognitive restructuring was the third most frequently used strategy by the students in our study sample, to face fears, daily stress, and technological stress associated with confinement and other situations generated by the pandemic.

In this study, the obtained mean score for the resilience variable with two factors was low compared with that obtained in an earlier study [112]; this may be because it was an evaluation carried out in a special pandemic situation. The variable resilience, comprising personal competence and acceptance of oneself and life, positively correlates with the problem solving coping strategy, which has been the most used by the students of the present sample, followed by the emotional expression strategy. Other research [1,113] has also shown the importance of adequate regulation of emotions and recommended taking a positive problem-solving attitude and generating pleasant emotions, either in person or through shared actions using networks and ICT. Our study has found correlations between resilience and the productive or functional problem-solving strategy; likewise, other research [98] has found that psychological resilience negatively correlates with depression, anxiety, and somatization scores. Thus, resilience is a highly relevant variable that should be encouraged in psychological intervention programs, especially in the public health emergency situations caused by the pandemic. Other studies conducted in other cultures such as China also show the importance of identifying the Chinese cultural beliefs towards the necessity of regulating emotions and the use of positive coping strategies to actively solve problems [58], and how active coping strategies based on social support are significantly correlated with a decrease in levels of psychological distress [114].

Other data from a study performed in the United States and Italy have also shown that the higher the anger contagion, the higher the level of tension, and the higher the joy contagion, the higher the predicted reduction of stress [115]. Furthermore, in another study, lower levels of positive emotions were identified in cases of self-isolation, and coping strategies focused on negative emotions and mental disengagement are associated with higher levels of pandemic anxiety, with a weak association between active and problem-oriented coping strategies and anxiety levels [116]. The study did not consider dysfunctional coping strategies, neither acceptance nor emotion-focused coping strategies unrelated to the deterioration of general well-being; however, it does consider the use of mental disengagement and substance use and denial, which were associated with lower well-being, namely lower levels of life satisfaction.

In our study, the data have also shown statistically significant associations between the variables of stress with COVID-19 and technological stress in both its total score and three dimensions: Technological overload, techno-invasion, and techno-complexity. Technological stress (Technological overload and techno-invasion) was found to be negatively correlated with higher use of the problem solving coping strategy; technological overload was also found to be negatively correlated with the emotional expression coping strategy, and techno-complexity was found to be negatively correlated with cognitive restructuring. Similarly, another study reported positive relationships between workload, techno-stressors, work-family conflict, and behavioral stress [22]. While the technological dimension has negative aspects such as work overload and information saturation through ICT [22], it is also worth mentioning the possibilities offered by ICT, networks, and media when their use is pedagogically appropriate and when they are used to keep people virtually connected with their contacts and support through video calls, chats, etc. Likewise, as it is reluctantly suggested in some studies, it is necessary to encourage research that considers the use of ICTs based on the neuroeducation approach, especially in the current pandemic situation [21,117], which could decrease psychological distress [118,119]. Furthermore, the Internet has differential effects; while it can connect people with resources and social support networks, it also allows the development of an information-seeking strategy that reinforces the constant checking of negative information and is associated with a greater presence of negative symptoms. Other studies $[120,121]$ pointed out that the COVID 19 pandemic has further increased students' reliance on technology, which could generate more stress, uncertainty, overload, and complexities. In another study in 
university students, [122] found differences in the causes and effects of stress between men and women, with both sexes using computers as one of the most frequent coping strategies.

Consistent with the findings of our study, it has been observed that excessive use of social networks can have a greater psychological impact; people who use social networks less show a higher level of impact, which is understood as a higher level of emotional distress [34]. The role of the Internet in these pandemic situations needs further examination, as some studies have shown a greater presence of mental health problems in people who use the Internet for longer periods of time continually searching for health information [32,122].

As in other studies [24,123], numerous psychoeducational implications can be derived from this type of study, such as those related to a more effective evaluation of the pandemic's effects on people's health, to develop psychological interventions that can reduce its impact on the creation of psychological and academic support programs to make people feel safer with a more empathetic communication system, the direct participation of the most vulnerable people, and more effective and accurate information and communication through the appropriate use of social networks and the media. Such use could contribute, among other aspects, to a more adaptive expression and emotional management in this pandemic situation. Moreover, as stated in other research (e.g., [84]), active, problemfocused coping, and positive coping strategies such as seeking social support, positive thinking, and problem solving should be encouraged, with the role of the media being fundamental in this respect [124].

Future studies should evaluate the impact of educational initiatives considering the resilience and self-esteem of and coping strategies used by university students. Further research should be multi-centered. A longitudinal study should be designed to assess how the variables investigated in this research can change as participants get older, and multi-level analysis could be performed by adding other study variables such as academic performance. This exercise's priority is a basic evaluation of the scores obtained in the first courses in which the students present more anxiety, fear, and academic stress [125], to guide them and design intervention programs to face the changes generated in this situation. We are promoting a program that contributes to the improvement of the use of more productive and effective coping strategies, resilience, and self-esteem as protective factors that contribute to reducing levels of fear, stress with COVID-19, and technological stress.

These findings might inform practical interventions that have a significant social impact. As a direction for future research, we call for further analysis based on students' class background, extracurricular work to earn their living, and how the pandemic affected their (and their families') education, work, and financial status. Future research needs to delve into the role that gender socialization might play in influencing coping skills. It should also continue examining gender-based differences in resilience and self-esteem. In this study, the female participants perceived themselves as "incapable of sufficient resilience," yet they reported higher self-esteem levels. This suggests the need to investigate how self-esteem affects coping strategies and perceptions of resilience for different genders. It is possible that because women are socialized from an early age to take on more responsibilities-that is, caring for children and the home in addition to earning wages-they have a higher capacity to endure and persevere, with the concomitant increase in stress and anxiety. Anxiety is known to cloud perception, so high anxiety levels might cause some women to fail to recognize their own resilience.

We intend to use these results to address stress-related problems beyond those caused by the pandemic, helping generate greater self-knowledge among university students. People need to assess their own fear, stress, and anxiety levels to adopt coping mechanisms and experience resilience. We intend to organize workshops to boost participants' selfknowledge so they can identify symptoms/behaviors that require coping mechanisms. The workshops will evaluate participants' stress and train them to use effective, productive coping strategies for daily stress. We will use an educational innovation project and tutorial 
action in the university environment. Inducing a positive appreciation of innovation [29] can help prevent techno-distress.

Given our present situation, future events are also likely to prompt fear, anxiety, and stress. Therefore, this innovation project could promote evaluations, academic sessions, and tutorial action to prevent academic and daily stress, improve self-esteem, and teach more effective and satisfactory coping strategies. Likewise, in coherence with the multidimensional model of Gratz and Roemer [67] that is defended in this study, guidelines could be provided to improve emotional regulation and social and psychological well-being among university students. The Academic Guidance Unit should design training actions and materials to guide students, provide them with tools to face technological stress, and help prevent overload and computational fatigue by improving perceived self-efficacy, time management, and task planning with adequate and satisfactory use of ICT.

Intervention programs that promote effective coping strategies against daily stress (e.g., active solution-oriented and positive attitude instead of keeping the problem to oneself) should be designed to ensure adequate emotional adjustment. In that sense, there is an increasing interest in developing programs of education for emotional regulation, educational coaching, etc. that emphasize the importance of designing activities that contribute to the acquisition of socioemotional competencies and that pay increasing attention to the emotional dimension $[76,126]$ and to stress management by promoting mindfulness [1]. Universities need to increase social support and offer services and programs that maximize protective factors and minimize risk factors [127]. Our study has also shown that contexts, such as education, must contribute to the promotion of social networks, technology, and Internet services to curb the effects of both the pandemic and the info-demic [128].

This study may be limited by the application of only self-report measures, and there is a need for a longitudinal study to see how scores change in different courses as well as in other degrees and centers. Moreover, student participants voluntarily took part in this study and they were not randomly selected. Therefore, the generalization of the results may be limited, and the data should be considered with due caution.

\section{Conclusions}

This research has shown that fear of COVID-19, daily stress, and technological stress are associated with resilience and coping strategies. Specifically, we identified an inverse relationship between the students' fear of COVID-19 and the use of the cognitive restructuring coping strategy, while we identified a direct positive correlation between the variable resilience (Personal competence and acceptance of oneself and life) and the problem solving coping strategy.

Technological stress (Technological overload and techno-invasion) was found to be negatively correlated with the use of the problem solving coping strategy. Likewise, technological overload was also found to be negatively correlated with the coping strategy, emotional expression, and techno-complexity was found to be negatively correlated with cognitive restructuring.

This information could help services prevent stress with COVID-19 in educational settings and finally lead to better self-esteem and academic performance.

Funding: This research received no external funding.

Institutional Review Board Statement: The study was conducted according to the guidelines of the Declaration of Helsinki, and approved by the Ethics Committee (Granada, Spain, 1574/CEIH/2020).

Informed Consent Statement: Informed consent was obtained from all subjects involved in the study.

Data Availability Statement: The data could be requested by the scientific community in the ethical terms to be determined.

Conflicts of Interest: The author declares no conflict of interest. 


\section{References}

1. Valero, N.; Vélez, M.; Durán, A.; Portillo, M. COVID-19 coping: Stress, fear, anxiety, and depression? Enferm. Inv. 2020, 5, 63-70.

2. Carleton, R.N. Into the Unknown: A review and synthesis of contemporary models involving uncertainty. J. Anxiety Disord. 2016, 39, 30-43. [CrossRef] [PubMed]

3. Pieh, C.; Budimir, S.; Delgadillo, J.; Barkham, M.; Fontaine, J.R.J.; Probst, T. Mental health during COVID-19 lockdown in the United Kingdom. Psychosom. Med. 2020. [CrossRef] [PubMed]

4. Rodríguez-Rey, R.; Garrido-Hernansaiz, H.; Collado, S. Psychological impact and associated factors during the initial stage of the coronavirus (COVID-19) pandemic among the general population in Spain. Front. Psychol. 2020, 11, 1540. [CrossRef]

5. Tzur Bitan, D.; Grossman-Giron, A.; Bloch, Y.; Mayer, Y.; Shiffmand, N.; Mendlovic, S. Fear of COVID-19 scale: Psychometric characteristics, reliability, and validity in the Israeli population. Psychiatry Res. 2020, 289, 113100. [CrossRef]

6. Wang, C.; Zhao, H. The Impact of COVID-19 on Anxiety in Chinese University Students. Front. Psychol. 2020, 11, 1168. [CrossRef]

7. Huremovic, D. Psychiatry of Pandemics. A Mental Health Response to Infection Outbreak, 1st ed.; Springer: Berlin/Heidelberg, Germany, 2019.

8. Ramírez-Ortiz, J.; Castro-Quintero, D.; Lerma-Córdoba, C.; Yela-Ceballos, F.; Escobar-Córdoba, F. Mental health consequences of the COVID-19 pandemic associated with social isolation. Colomb. J. Anesthesiol. 2020, 48, e930. [CrossRef]

9. Sun, L.; Sun, Z.; Wu, L.; Zhu, Z.; Zhang, F.; Shang, Z.; Jia, Y.; Gu, J.; Zhou, Y.; Wang, Y.; et al. Prevalence and risk factors for acute posttraumatic stress disorder during the COVID-19 outbreak. J. Affect. Disord. 2021, 283, 123-129. [CrossRef]

10. Colizzi, M.; Bortoletto, R.; Silvestri, M.; Mondini, F.; Puttini, E.; Cainelli, C.; Zoccante, L. Medically unexplained symptoms in the times of Covid-19 pandemic: A casereport. Brain Behav. Immun. 2020, 100073. [CrossRef]

11. Sher, L. The impact of the COVID-19 pandemic on suicide rates. QJM: Monthly journal of the Association of Physicians, hcaa202. Adv. Online Publ. 2020. [CrossRef]

12. Brooks, S.K.; Webster, R.K.; Smith, L.E.; Woodland, L.; Wessely, S.; Greenberg, N.; Rubin, G.J. The psychological impact of quarantine and how to reduce it: Rapid review of the evidence. Lancet 2020, 39, 912-920. [CrossRef]

13. Panchal, N.; Kamal, R.; Orgera, K.; Cox, C.; Garfield, R.; Hamel, L. The Implications of COVID-19 for Mental Health and Substance Use. 2020. Available online: https:/ / www.kff.org/report-section/the-implications-of-covid-19-for-mental-healthand-substance-use-issue-brief/ (accessed on 5 May 2020).

14. Medina, R.M.; Jaramillo-Valverde, L. COVID-19: Quarantine and Psychological Impact on the population/El COVID-19: Cuarentena y su Impacto Psicológico en la población/COVID-19: Quarentena e seu impacto psicológico na população. Prepr. Engl. Scielo Prepr. 2020. [CrossRef]

15. Li, S.; Wang, Y.; Xue, J.; Zhao, N.; Zhu, T. The Impact of COVID-19 Epidemic Declaration on Psychological Consequences: A Study on Active Weibo Users. Int. J. Environ. Res. Public Health 2020, 17, 2032. [CrossRef] [PubMed]

16. Park, C.L.; Russell, B.S.; Fendrich, M.; Finkelstein-Fox, L.; Hutchison, M.; Becker, J. Americans' COVID-19 stress, coping, and adherence to CDC guidelines. J. Gen. Intern. Med. 2020, 35, 2296-2303. [CrossRef] [PubMed]

17. Piña-Ferrer, L. The COVID 19: Psychological impact on human beings. Interdiscip. Refereed J. Health Sci. Salud Y Vida 2020, 4. [CrossRef]

18. Findlay, L.C.; Arim, R.; Koen, D. Understanding the perceived mental health of Canadians during the COVID-19 pandemic. Health Rep. 2020, 31, 22-27.

19. Psychosom Nimrod, G. Changes in Internet Use When Coping With Stress: Older Adults During the COVID-19 Pandemic. Am. J. Geriatr. Psychiatry 2020, 28, 1020-1024. [CrossRef]

20. AlAteeq, D.A.; Aljhani, S.; AlEesa, D. Perceived stress among students in virtual classrooms during the COVID-19 outbreak in KSA. Taibah Univ. Medical. Sci. 2020, 15, 398-403.

21. Espino-Díaz, L.; Fernandez-Caminero, G.; Hernandez-Lloret, C.-M.; Gonzalez-Gonzalez, H.; Alvarez-Castillo, J.-L. Analyzing the Impact of COVID-19 on Education Professionals. Toward a Paradigm Shift: ICT and Neuroeducation as a Binomial of Action. Sustainability 2020, 12, 5646. [CrossRef]

22. Molino, M.; Ingusci, E.; Signore, F.; Manuti, A.; Giancaspro, M.L.; Russo, V.; Zito, M.; Cortese, C.G. Wellbeing Costs of Technology Use during Covid-19 Remote Working: An Investigation Using the Italian Translation of the Technostress Creators Scale. Sustainability 2020, 12, 5911. [CrossRef]

23. Tarafdar, M.; Tu, Q.; Ragu-Nathan, B.S.; Ragu-Nathan, T.S. The impact of technostress on role stress and productivity. J. Manag. Inf. Syst. 2007, 24, 301-328. [CrossRef]

24. Ozamiz-Etxebarria, N.; Dosil-Santamaria, M.; Picaza-Gorrochategui, M.; Idoiaga-Mondragon, N. Stress, anxiety, and depression levels in the initial stage of the COVID-19 outbreak in a population sample in the northern Spain. Cad. Saúde Pública 2020, 36, e00054020. [CrossRef] [PubMed]

25. Duan, L.; Zhu, G. Psychological interventions for people affected by the COVID-19 epidemic. Lancet Psychiatry 2020, 7, 300-302. [CrossRef]

26. Rodríguez, S.; Valle, A.; Piñeiro, I.; Rodríguez-Llorente, C.; Guerrero, E.; Martins, L. Sociodemographic Characteristics and Stress of People from Spain Confined by COVID-19. Eur. J. Investig. Health Psychol. Educ. 2020, 10, 1095-1105. [CrossRef]

27. Arnetz, B.B. Technological stress: Psychophysiological aspects of working with modern information technology. Scand. J. Work. Environ. Health 1997, 23 (Suppl. 3), 97-103. [PubMed] 
28. Smith, M.J. Psychosocial aspects of working with video display terminals (VDTs) and employee physical and mental health. Ergonomics 1997, 40, 1002-1015. [CrossRef]

29. La Torre, G.; Esposito, A.; Sciarra, I.; Chiappetta, M. Definition, symptoms and risk of techno-stress: A systematic review. Int. Arch. Occup. Environ. Health 2019, 92, 13-35. [CrossRef] [PubMed]

30. Raja Zirwatul Aida, R.I.; Azlina, A.B.; Siti Balqis, M.N. Techno Stress: A Study Among Academic and Non Academic Staff. In Ergonomics and Health Aspects of Work with Computers. EHAWC; Dainoff, M.J., Ed.; Lecture Notes in Computer Science; Springer: Berlin/Heidelberg, Germany, 2007; Volume 4566. [CrossRef]

31. Salazar-Concha, C.; Ficapal-Cusí, P.; Boada-Grau, J.; Camacho, L.J. Analyzing the evolution of technostress: A science mapping approach. Heliyon 2021, 12, e06726. [CrossRef]

32. Gualano, M.R.; Lo Moro, G.; Voglino, G.; Bert, F.; Siliquini, R. Effects of Covid-19 Lockdown on Mental Health and Sleep Disturbances in Italy. Int. J. Environ. Res. Public Health 2020, 17, 4779. [CrossRef] [PubMed]

33. Gurvich, C.; Thomas, N.; Thomas, E.H.; Hudaib, A.R.; Sood, L.; Fabiatos, K.; Sutton, K.; Isaacs, A.; Arunogiri, S.; Sharp, G.; et al. Coping styles and mental health in response to societal changes during the COVID-19 pandemic. Int. J. Soc. Psychiatry 2020, 4, 20764020961790. [CrossRef]

34. Parrado González, A.; León Jariego, J.C. COVID-19: Factors associated with emotional distress and psychic morbidity in Spanish population. Span. J. Public Health 2020, 94, e202006058.

35. Aslan, H.; Pekince, H. Nursing students' views on the COVIV-19 pandemic and their percieved stress levels. Perspect. Psychiatr. Care 2020, 1-7. [CrossRef]

36. Joseph, N.; Nallapati, A.; Machado, M.X.; Varsha, N.; Matele, S.; Muthusamy, N.; Sinha, A. Assessment of academic stress and its coping mechanisms among medical undergraduate students in a large Midwestern university. Curr. Psychol. 2020, 7903. [CrossRef]

37. Folkman, S.; Moskowitz, J.T. Coping: Pitfalls and promise. Annu. Rev. Psychol. 2004, 55, 745-774. [CrossRef] [PubMed]

38. Lazarus, R.S. Psychological Stress, and the Coping Process.; McGraw-Hill: New York, NY, USA, 1966.

39. Lazarus, R.; Folkman, S. Stress, Appraisal, and Coping; Springer Publishing Company: New York, NY, USA, 1984.

40. Compas, B.E.; Connor-Smith, J.K.; Saltzman, H.; Thomsen, A.H.; Wadsworth, M.E. Coping with stress during childhood and adolescence: Problems, progress, and potential in theory and research. Psychol. Bull. 2001, 127, 87-127. [CrossRef]

41. Frydenberg, E.; Lewis, R. Adolescent Coping Scale: Administrator's Manual; Australian Council for Educational Research: Hawthorn, Victoria, Australia, 1993.

42. Trianes, M.V. Estrés en la Infancia; Narcea Publishing: Madrid, Spain, 2002.

43. Zeidner, M.; Saklofske, D. Adaptive and maladaptive coping. In Handbook of Coping: Theory, Research, Applications; Zeidner, M., Endler, N.E., Eds.; Wiley: Nueva York, NY, USA, 1996.

44. Frydenberg, E.; Lewis, R. A replication study of the structure of the adolescent coping scale: Multiple forms and applications of a self-report inventory in a counseling and research context. Eur. J. Psychol. Assess. 1996, 12, 224-235. [CrossRef]

45. Maghan, M. Problem Solving Style and Coping Strategies: Effects of Perceived Stress. Creat. Educ. 2017, 8, 2332-2351. [CrossRef]

46. Cabanach, R.G.; Valle, A.; Rodríguez, S.; Piñeiro, I.; Freire, C. Academic stress coping scale. Iberoam. J. Psychol. Health 2010, 1, 51-64.

47. Compas, B.E.; Orosan, P.G.; Grant, K.E. Adolescent stress and coping: Implications for psychopathology during adolescence. J. Adolesc. 1993, 16, 331-349. [CrossRef]

48. Lapointe, V.; Marcotte, D. Gender typed characteristics and coping strategies of depressed adolescents. Eur. Rev. Appl. Psychol. 2000, 50, 451-460.

49. Seiffge-Krenke, I. Causal links between stressful events, coping style, and adolescent symptomatology. J. Adolesc. 2000, 23, 675-691. [CrossRef]

50. Cappa, K.; Moreland, A.; Conger, J.; Dumas, J.; Conger, A. Bidirectional relationships between parenting stress and child coping competence: Findings from the pace study. J. Child. Fam. Stud. 2011, 20, 334-342. [CrossRef] [PubMed]

51. González, R.; Montoya, M.; Casullo, M.; Bernabéu, J. Relationship between coping styles and strategies and psychological well-being in adolescents. Psicothema 2002, 14, 363-368.

52. Urzúa, A.; Jarne, A. Quality of life and coping styles in people with chronic pathologies. R. Interam. Psicol. 2008, 42, 151-160.

53. Roberts, R.E.; Roberts, C.R.; Chen, I.G. Fatalism and risk of adolescent depression. Psychiatry 2000, 63, 239-252. [CrossRef]

54. Wright, M.; Banerjee, R.; Hoek, W.; Rieffe, C.; Novin, S. Depression and social anxiety in children: Differential links with coping strategies. J. Abnorm. Child. Psychol. 2010, 38, 405-419. [CrossRef]

55. Wadsworth, M.; Compas, B. Coping with family confl ict and economic strain: The adolescent perspective. J. Res. Adolesc. 2002, 12, 243-274. [CrossRef]

56. Seiffge-Krenke, I.; Stemmler, M. Factors contributing to gender differences in depressive symptoms: A test of three developmental models. J. Youth Adolesc. 2002, 31, 405-417. [CrossRef]

57. Baloch, G.M.; Kamaludin, K.; Chinna, K.; Sundarasen, S.; Nurunnabi, M.; Khoshaim, H.B.; Hossain, S.F.A.; Sukayt, A.A.; Baloch, L.G. Coping with COVID-19: The Strategies Adapted by Pakistani Students to Overcome Implications. Int. J. Environ. Res. Public Health 2021, 18, 1799. [CrossRef] [PubMed]

58. Xia, M.; Duan, C. Stress Coping of Chinese International Students in Face of COVID 19 Pandemic: Cultural Characteristics. Int. J. Ment. Health Promot. 2020, 22, 159-172. [CrossRef] 
59. Capone, V.; Caso, D.; Donizzetti, A.R.; Procentese, F. University Student Mental Well-Being during COVID-19 Outbreak: What Are the Relationships between Information Seeking, Perceived Risk and Personal Resources Related to the Academic Context? Sustainability 2020, 12, 7039. [CrossRef]

60. Yeo, K.; Frydenberg, E.; Northam, E.; Deans, J. Coping with stress among preschool children and associations with anxiety level and controllability of situations. Aust. J. Psychol. 2014, 66, 93-101. [CrossRef]

61. Evans, L.D.; Kouros, C.; Frankel, S.A.; McCauley, E.; Diamond, G.S.; Schloredt, K.A.; Garber, J. Longitudinal relations between stress and depressive symptoms in Youth: Coping as a mediator. J. Abnorm. Child. Psychol. 2015, 43, 355-368. [CrossRef]

62. Ávila-Quiñones, A.S.; Montaña, G.; Jiménez-Arenas, D.; Burgos, J. Coping styles and strategies and academic performance: An empirical review. Enfoques 2014, 1, 15-44.

63. Viñas, F.; González, M.; García, Y.; Malo, S.; Casas, F. Coping styles and strategies and their relationship with personal well-being in a sample of adolescents. An. Psicol. 2015, 31, 226-233. [CrossRef]

64. Eisenberg, N.; Fabes, R.A.; Karbon, M.; Murphy, B.; Juhnke, C. The relations of dispositional prosocial behavior to emotionality, regulation, and social functioning. Child. Dev. 1996, 67, 974-992. [CrossRef]

65. Gross, J.J. The emerging field of emotion regulation: An integrative review. Rev. Gen. Psychol. 1998, 2, 271-299. [CrossRef]

66. Thompson, R.A. Emotional regulation and emotional development. Educ. Psychol. Rev. 1991, 3, 269-307. [CrossRef]

67. Gratz, K.L.; Roemer, L. Multidimensional assessment of emotion regulation and dysregulation: Development, factor structure, and initial validation of the difficulties in emotion regulation scale. J. Psychopathol. Behav. Assess 2004, 26, 41-54. [CrossRef]

68. Hall, K.; Youssef, G.; Simpson, A.; Sloan, E.; Graeme, L.; Perry, N.; Moulding, R.; Baker, A.L.; Beck, A.K.; Staiger, P.K. An Emotion Regulation and Impulse Control (ERIC) Intervention for Vulnerable Young People: A Multi-Sectoral Pilot Study. Front. Psychol. 2021, 12, 554100. [CrossRef] [PubMed]

69. Goodman, K.L.; Southam-Gerow, M.A. The regulating role of negative emotions in children's coping with peer rejection. Child. Psychiatry Hum. Dev. 2010, 41, 515-534. [CrossRef] [PubMed]

70. Sandler, I.N.; Tein, J.-Y.; Mehta, P.; Wolchik, S.; Ayers, T. Coping efficacy and psychological problems of children of divorce. Child. Dev. 2000, 71, 1099-1118. [CrossRef] [PubMed]

71. Eisenberg, N.; Fabes, R.A.; Bernzweig, J.; Karbon, M.; Poulin, R.; Hanish, L. The relations of emotionality and regulation to preschoolers' social skills and sociometric status. Child. Dev. 1993, 64, 1418-1438. [CrossRef] [PubMed]

72. Jackson, Y.; Warren, J. Appraisal, social support, and life-events: Predicting outcome behavior in school-age children. Child. Dev. 2000, 71, 1441-1457. [CrossRef] [PubMed]

73. Lengua, L.J.; Long, A.C. The role of emotionality and self-regulation in the appraisal-coping process: Tests of direct and moderating effects. J. Appl. Dev. Psychol. 2002, 23, 471-493. [CrossRef]

74. Fabes, R.A.; Eisenberg, N. Young children's coping with interpersonal anger. Child. Dev. 1992, 63, 116-128. [CrossRef]

75. Wang, J.; Wang, Z.; Liu, X.; Yang, X.; Zheng, M.; Baia, X. The impacts of a COVID-19 epidemic focus and general belief in a just world on individual emotions. Pers. Individ. Differ. 2021, 168, 110349. [CrossRef]

76. Morales, F.M. Relationships between coping with everyday stress, self-concept, social skills, and emotional intelligence. Eur. J. Psychol. Educ. 2017, 10, 41-48.

77. Haktanir, A.; Watson, J.C.; Ermis-Demirtas, H.; Karaman, M.A.; Freeman, P.D.; Kumaran, A.; Streeter, A. Resilience, Academic Self-Concept, and College Adjustment Among First-Year Students. J. Coll Stud. Ret. 2018, 23, 161-178. [CrossRef]

78. Willis, K.D.; Burnett, H.J. The power of stress: Perceived stress and its relationship with rumination, self-concept clarity, and resilience. N. Am. J. Psychol. 2016, 18, 483-498.

79. Morales, F.M.; Molina, J.; Mercadé, P. Development of self-esteem in university students through an experiential training program. In Begoña Medina Gómez Guillermina Jiménez López, Mónica Fernández Morilla, Cutting-Edge Content in the EHEA; Ediciones Pirámide: Madrid, Spain, 2019; pp. 253-269.

80. Pallares, M. Self-Esteem. How to Cultivate It in a Healthy Way; Mensajero: Bilbao, Spain, 2011.

81. Ortega, J.; Sánchez-Queija, I. Psychological variables involved in learning: The meaning of learning. In Manual de Psicología de la Educación. Para Docentes de Educación Infantil y Primaria, 2nd ed.; Prados, M.M., Ed.; Pirámide: Madrid, Spain, 2016 ; pp. 85-105.

82. Burns, R.B. Self-Concept: Theory, Measurement, Development, and Behavior; Ediciones EGA: Bilbao, Spain, 1990.

83. Rosenberg, M. Society and the Adolescent Self-Image; Princeton University Press: Princeton, NJ, USA, 1965.

84. Chew, Q.H.; Chia, F.L.-A.; Ng, W.K.; Lee, W.C.I.; Tan, P.L.L.; Wong, C.S.; Puah, S.H.; Shelat, V.G.; Seah, E.-J.D.; Huey, C.W.T.; et al. Perceived Stress, Stigma, Traumatic Stress Levels and Coping Responses amongst Residents in Training across Multiple Specialties during COVID-19 Pandemic-A Longitudinal Study. Int. J. Environ. Res. Public Health 2020, 17, 6572. [CrossRef] [PubMed]

85. Seçer, İ.; Ulaş, S.; Karaman-Özlü, Z. The Effect of the Fear of COVID-19 on Healthcare Professionals' Psychological Adjustment Skills: Mediating Role of Experiential Avoidance and Psychological Resilience. Front. Psychol. 2020, 11, 561536. [CrossRef] [PubMed]

86. Ferreira, R.J.; Buttell, F.; Cannon, C. COVID-19: Immediate Predictors of Individual Resilience. Sustainability 2020, $12,6495$. [CrossRef]

87. Fiorentino, M.T. The construction of resilience in the improvement of quality of life and health. Suma Psicol. 2008, 15, 95-114.

88. González-Torres, M.C.; Artuch, R. Resilience profiles and coping strategies at university: Contextual and demographic variables. Rev. Electron. Investig. Psicoeduc. Psigopedag. 2014, 12, 621-648. [CrossRef]

89. Salgado, A.C. Methods and instruments for measuring resilience: A Peruvian alternative. Liberabit 2005, 11, 41-48. 
90. Ungar, M. The social construction of resilience among "problema" Youth in out-of-home placement: A study of health-enhancing deviance. Child. Youth Care Forum 2003, 30, 137-154. [CrossRef]

91. Wang, D.; Nan, J.K.M.; Zhang, R. Structured group sandplay to improve the resilience of college students: A pilot study. Arts Psychother. 2017, 55, 186-194. [CrossRef]

92. Bernalte, A.; Miret, M.T.; Navarro, C.M.; Ruiz, S.; Bermúdez, M.T.; Lupiani, M.M. Las dificultades en el proceso académico susceptibles de producir resiliencia, según alumnos de enfermería es-pañoles. Cult. Care 2009, 26, 65-86.

93. United Nations Educational, Scientific and Cultural Organization (UNESCO). World Conference on Higher Education-2009: The New Dynamics of Higher Education and Research for Social Change and Development (Communiqué) 2009; UNESCO: Paris, France, 2009.

94. Organization for Economic Cooperation and Development (OECD). The Definition and Selection of Key Competencies. Executive Summary. 2005. Available online: https: / / www.oecd.org/pisa/35070367.pdf (accessed on 2 July 2020).

95. Belaunzaran Mendizabal, J. Descriptive analysis of EuroPsy: A competency-based model. Is this model applicable to specialised health training in clinical psychology? Educ. Med. 2019, 20, 154-162. Available online: https://www.sciencedirect.com/science/ article/pii/S157518131830216X (accessed on 2 July 2020).

96. Vagni, M.; Maiorano, T.; Giostra, V.; Pajardi, D. Hardiness, Stress and Secondary Trauma in Italian Healthcare and Emergency Workers during the COVID-19 Pandemic. Sustainability 2020, 12, 5592. [CrossRef]

97. Domínguez-Salas, S.; Gómez-Salgado, J.; Andrés-Villas, M.; Díaz-Milanés, D.; Romero-Martín, M.; Ruiz-Frutos, C. Psychoemotional approach to psychological distress related to the COVID-19 pandemic in Spain: A cross-sectional observational study. Health 2020, 8, 3.

98. Ran, L.; Wang, W.; Ai, M.; Kong, Y.; Chen, J.; Kuang, L. Psychological resilience, depression, anxiety, and somatization symptoms in response to COVID-19: A study of the general population in China at the peak of its epidemic. Soc. Sci. Med. 2020, $262,113261$. [CrossRef]

99. Ahorsu, D.K.; Lin, C.Y.; Imani, V.; Saffari, M.; Griffiths, M.D.; Pakpour, A.H. The Fear of COVID-19 Scale: Development and Initial Validation. Int. J. Ment. Health Addict. 2020, 1-9. [CrossRef] [PubMed]

100. Adalberto Campo-Arias, A.; Pedrozo-Cortés, M.J.; Pedrozo-Pupo, J.C. COVID-19 pandemic-related perceived stress scale: An exploration of online psychometric performance. Rev. Colomb Psiquiatr. 2020, 49. [CrossRef]

101. Ragu-Nathan, T.S.; Tarafdar, M.; Ragu-Nathan, B.S.; Tu, Q. The consequences of technostress for end users in organizations: Conceptual development and empirical validation. Inf. Syst. Res. 2008, 19, 417-433. [CrossRef]

102. Wagnild, G.M. The Resilience Scale User's Guide for the US English Version of the Resilience Scale and the 14-Item Resilience Scale; The Resilience Center: Worden, MT, USA, 2009.

103. Sánchez-Teruel, D.; Robles-Bello, M.A. Escala de Resiliencia 14 ítems (RS-14): Propiedades Psicométricas de la Versión en Español. RIDEP 2015, 40, 103-113.

104. Rosenberg, M. Society and the Adolescent Self-Image; Wesleyan University Press: Middeltown, CT, USA, 1989.

105. Baños, R.M.; Guillén, V. Psychometric characteristics in normal and social phobic samples for a Spanish version of Rosenberg Self Esteem Scale. Psychol. Rep. 2000, 87, 269-274. [CrossRef]

106. Cano García, F.J.; Rodríguez Franco, L.; García Martínez, J. Spanish adaptation of the Coping Strategies Inventory. Actas Esp. Psiquiatr. 2007, 35, 29-39. Available online: https://www.researchgate.net/publication/235419673_Adaptacion_Espanola_del_ Inventario_de_Estrategias_de_Afrontamiento (accessed on 2 July 2020).

107. Asmundson, G.J.G.; Taylor, S. Coronaphobia: Fear and the 2019-nCoV outbreak. J. Anxiety Dis. 2020, 70, 102196. [CrossRef]

108. Rnka, R.; Lorencova, R. Fear, anger, and media-induced trauma during the outbreak of COVID-19 in the Czech Republic. Psychol. Trauma Theory Res. Pract. Policy 2020, 12, 546-549. [CrossRef]

109. Usher, K.; Durkin, J.; Bhullar, N. The COVID-19 pandemic and mental health impacts. Int. J. Ment. Health Nurs. 2020, 29 , 315-318. [CrossRef] [PubMed]

110. Roy, D.; Tripathy, S.; Kar, S.; Sharma, N.; Verma, S.; Kaushal, V. Study of knowledge, attitude, anxiety \& perceived mental healthcare need in Indian population during COVID-19 pandemic. Asian J. Psychiatry 2020, 51, 102083.

111. Guo, J.; Feng, X.L.; Wang, X.H.; van IJzendoorn, M.H. Coping with COVID-19: Exposure to COVID-19 and Negative Impact on Livelihood Predict Elevated Mental Health Problems in Chinese Adults. Int. J. Environ. Res. Public Health. 2020, $17,3857$. [CrossRef] [PubMed]

112. Sánchez-Teruel, D.; Robles-Bello, M.A. Resilience Scale 14 items (RS-14): Psychometric properties of the Spanish Version. Rev. Iberoam. Diagnóstico Evaluación Avaliação Psicológica 2015, 2, 103-113.

113. Spinelli, M.; Lionetti, F.; Setti, A.; Fasolo, M. Parenting Stress During the COVID-19 Outbreak: Socioeconomic and Environmental Risk Factors and Implications for Children Emotion Regulation. Fam. Process. 2020. [CrossRef]

114. Yu, H.; Li, M.; Li, Z.; Xiang, W.; Yuan, Y.; Liu, Y.; Li, Z.; Xiong, Z. Coping style, social support, and psychological distress in the general Chinese population in the early stages of the COVID-19 epidemic. BMC Psychiatry 2020, 20, 426. [CrossRef] [PubMed]

115. Petitta, L.; Probst, T.M.; Ghezzi, V.; Barbaranelli, C. Economic stress, emotional contagion, and safety outcomes: A cross-country study. WORK 2020, 66, 421-435. [CrossRef]

116. Rasskazova, E.I.; Leontiev, D.A.; Lebedeva, A.A. Pandemic as a Challenge to Subjective Well-Being: Anxiety and Coping. Konsul'tativnaya psikhologiya i psikhoterapiya. Couns. Psychol. Psychother. 2020, 28, 90-108. [CrossRef] 
117. Espino-Díaz, L.; Alvarez-Castillo, J.-L.; Gonzalez-Gonzalez, H.; Hernandez-Lloret, C.-M.; Fernandez-Caminero, G. Creating Interactive Learning Environments through the Use of Information and Communication Technologies Applied to Learning of Social Values: An Approach from Neuro-Education. Soc. Sci. 2020, 9, 72. [CrossRef]

118. Idris, H. Utilization of Teleconsultation: Mitigation in Handling Mental Disorders in the COVID-19 Era. Int. J. Ment. Health Addict. 2020. [CrossRef] [PubMed]

119. Zhang, M.; Smith, H.E. Digital Tools to Ameliorate Psychological Symptoms Associated With COVID-19: Scoping Review. Med. Internet Res. 2020, 22, e19706. [CrossRef] [PubMed]

120. Sigurvinsdottir, R.; Thorisdottir, I.E.; Gylfason, H.F. The Impact of COVID-19 on Mental Health: The Role of Locus on Control and Internet Use. Int. J. Environ. Res. Public Health 2020, 17, 6985. [CrossRef] [PubMed]

121. Abbas, A.; Eliyana, A.; Ekowati, D.; Saud, M.; Raza, A.; Wardani, R. Data set on coping strategies in the digital age: The role of psychological well-being and social capital among university students in Java Timor, Surabaya, Indonesia. Data Brief. 2020, 30, 105583. [CrossRef]

122. Mazo, G.N. Causes, Effects of Stress, and the Coping Mechanism of the Bachelor of Science in Information Technology Students in A Philippine University. J. Educ. Learn. 2015, 9, 71-78. [CrossRef]

123. Smirni, P.; Lavanco, G.; Smirni, D. Anxiety in Older Adolescents at the Time of COVID-19. J. Clin. Med. 2020, 9, 3064. [CrossRef]

124. Anwar, A.; Malik, M.; Raees, V.; Anwar, A. Role of Mass Media and Public Health Communications in the COVID-19 Pandemic. Cureus 2020, 12, e10453. [CrossRef]

125. Morales-Rodríguez, F.M.; Pérez-Mármol, J.M.; Brown, T. Education burnout and engagement in occupational therapy undergraduate students and its associated factors. Front. Psychol. 2019, 10, 2889. [CrossRef]

126. López, C.; Valls, C. Educational Coaching: Emotions, at the Service of Learning; SM: Madrid, Spain, 2013.

127. Lechner, W.V.; Laurene, K.R.; Patel, S.; Anderson, M.; Grega, C.; Kenne, D.R. Changes in alcohol use as a function of psychological distress and social support following COVID-19 related University closings. Addict. Behav. 2020, 110, 106527. [CrossRef]

128. Dubey, S.; Biswas, P.; Ghosh, R.; Chatterjee, S.; Dubey, M.J.; Chatterjee, S.; Lahiri, D.; Lavie, C.J. Psychosocial impact of COVID-19. Diabetes Metab. Syndr. 2020, 14, 779-788. [CrossRef] 